\title{
Otago Glaucoma Surgery Outcome Study: long term results of cataract extraction combined with Molteno implant insertion or trabeculectomy in primary glaucoma
}

\author{
A C B Molteno, K W Whittaker, T H Bevin, P Herbison
}

Br J Ophthalmol 2004;88:32-35

Background/Aims: To describe the long term results of cases of cataract extraction combined with either Molteno implant insertion or trabeculectomy for primary open angle glaucoma.

Methods: This prospective case series followed cases which had cataract extraction and Molteno implant insertion (45 eyes) or trabeculectomy (94 eyes) followed up for a mean of 5.3 years and 3.9 years respectively.

Results: Cataract extraction and Molteno implant insertion or trabeculectomy controlled the intraocular pressure at $21 \mathrm{mmHg}$ or less with a probability of $1.00195 \% \mathrm{Cl} 0.93$ to 1.00$)$ at 10 years or more after operation and $0.94195 \%$ $\mathrm{Cl} 0.89$ to 0.99$)$ and $0.73(95 \% \mathrm{Cl} 0.46$ to 0.99$)$ at five and 10 years after operation respectively.

Conclusions: Cataract extraction combined with insertion of Molteno implants or trabeculectomy controlled the intraocular pressure in $100 \%(45 / 45)$ and $94 \%(88 / 94)$ of cases respectively.

$\mathrm{H}$ istorically, cataract extraction has been combined with iridencleisis, trephination, sclerectomy, and thermal sclerostomy. ${ }^{1}$ These procedures are associated with an increased complication rate and the hypotensive effect is less predictable. With advances in surgical technique there has been renewed interest and more widespread acceptance of simultaneous surgery, the modern day "gold standard" of which is phacotrabeculectomy.

Two recent reviews highlight a relative lack of controlled studies regarding this subject, ${ }^{2}{ }^{3}$ however the weight of evidence indicates that phacotrabeculectomy may be associated with poorer long term intraocular pressure (IOP) control compared with trabeculectomy alone, but it reduces the frequency and magnitude of early IOP spikes compared with cataract extraction alone.

This report describes the surgical technique and results obtained following cataract extraction combined with insertion of Molteno implant ${ }^{4}$ (45 cases) or trabeculectomy (94 cases) for primary open angle glaucoma at Dunedin Hospital, New Zealand between 1986 and 2001.

\section{PATIENTS AND METHODS}

The Otago Glaucoma Surgery Outcome Study has been previously described. ${ }^{56}$

\section{Case selection}

Cases with co-existing primary open angle glaucoma and visually significant cataract which had combined cataract and glaucoma surgery at Dunedin Hospital between 1986 and
June 2001 were identified from the computerised database of the Otago Glaucoma Surgery Outcome Study. Cataract extraction was combined with trabeculectomy, except in cases with additional risk factors or where a higher complication rate was expected from trabeculectomy, wherein a Molteno implant was inserted (see Table 1). Phacoemulsification replaced extracapsular surgery as the standard technique for cataract extraction in 1993.

\section{Surgical technique}

Cataract extraction combined with insertion of Molteno implant

The 5/0 polyglycolic acid (Vicryl) (Ethicon Inc, Johnson \& Johnson, Somerville, NJ, USA) tie technique was used in all cases. A fornix based flap of Tenon's tissue and conjunctiva was raised to expose one or two superior quadrants of the sclera followed by raising of a half thickness scleral flap extending from the line of insertion of the recti to the limbus. Double-plate drains (10 eyes) were sutured to the sclera posterior to the flap either side of the superior rectus muscle, with single-plate drains ( 35 eyes) being sutured to either the nasal or temporal side of the muscle. The anterior chamber drainage tube was occluded by tying a Vicryl suture around its exterior, where it joined the plate of the implant. This tube was then trimmed to a $45^{\circ}$ bevel facing forward. At this stage, cataract extraction with intraocular lens implantation was carried out by either standard extracapsular or phacoemulsification techniques. Extracapsular extraction was achieved via a limbal incision extending in one direction circumferentially from the scleral flap (ECCE implant). Phacoemulsification was performed via a clear corneal section or scleral tunnel remote from the scleral flap (phaco implant). After placement of the intraocular lens, closure of the eye and reformation of the anterior chamber, the operation was concluded by inserting the trimmed drainage tube into the anterior chamber via a self-sealing track produced by the tip of a 22 gauge needle inserted through the limbal tissues under the scleral flap.

Cataract extraction combined with trabeculectomy In cases of trabeculectomy combined with extracapsular cataract extraction (ECCE-trab), either a limbus based or fornix based conjunctival flap was fashioned. A scleral flap (approximately $4 \times 4 \mathrm{~mm}$ ) was prepared and the corneoscleral incision extended either side of the flap. After nucleus expression, cortex aspiration and intraocular lens insertion, three or four sutures were placed either side of the scleral flap. A full thickness block of trabecular tissue was excised and a peripheral iridectomy was performed. Two 10/0 nylon sutures were placed at the posterior margin of the scleral flap, and the conjunctiva and Tenon's tissue closed in one or two layers with 8/0 silk or Vicryl. Phacotrabeculectomies (phacotrab) were performed via one or two sites. For all two site 
Table 1 Patient characteristics and preoperative state and risk factors*

\begin{tabular}{|c|c|c|}
\hline & $\begin{array}{l}\text { Molteno implant } \\
n=45 \text { eyes } \\
\text { ( } 43 \text { patients) }\end{array}$ & $\begin{array}{l}\text { Trabeculectomy } \\
\mathrm{n}=94 \text { eyes } \\
\text { (79 patients) }\end{array}$ \\
\hline Sex & $\begin{array}{l}29 \text { male; } 14 \\
\text { female }\end{array}$ & $\begin{array}{l}30 \text { male; } 49 \\
\text { female }\end{array}$ \\
\hline Age at operation (years) & $\begin{array}{l}78.7 \text { (range } 65- \\
95 \text { ) }\end{array}$ & $78.5(56-92)$ \\
\hline \multicolumn{3}{|l|}{ Diagnosis } \\
\hline Primary open angle glaucoma & $23(51 \%)$ & $72(77 \%)$ \\
\hline $\begin{array}{l}\text { Primary open angle glaucoma } \\
\text { with pseudoexfoliation }\end{array}$ & $22(49 \%)$ & $22(23 \%)$ \\
\hline \multicolumn{3}{|l|}{ Preoperative visual acuity } \\
\hline$\geqslant 20 / 30$ & $2(4 \%)$ & $15(16 \%)$ \\
\hline$<20 / 30-20 / 400>$ & $32(71 \%)$ & $63(67 \%)$ \\
\hline$\leqslant 20 / 400$ & $11(24 \%)$ & $16(17 \%)$ \\
\hline \multicolumn{3}{|l|}{$\begin{array}{l}\text { Preoperative area of field } \\
\text { remaining }\end{array}$} \\
\hline $80-100 \%$ & $14(31 \%)$ & $25(27 \%)$ \\
\hline $60-79 \%$ & $6(13 \%)$ & $23(25 \%)$ \\
\hline $40-59 \%$ & $7(16 \%)$ & $19(20 \%)$ \\
\hline $20-39 \%$ & $11(24 \%)$ & $10(11 \%)$ \\
\hline $0-19 \%$ & $7(16 \%)$ & $10(11 \%)$ \\
\hline Not known & 0 & $6(6 \%)$ \\
\hline $\begin{array}{l}\text { Advanced field loss threatening } \\
\text { fixation }\end{array}$ & $7(16 \%)$ & $6(6 \%)$ \\
\hline $\begin{array}{l}\text { Very advanced field loss involving } \\
\text { fixation }\end{array}$ & $7(16 \%)$ & $11(12 \%)$ \\
\hline Cornea guttata & $9(20 \%)$ & 0 \\
\hline \multicolumn{3}{|l|}{ Previous ocular surgery } \\
\hline Trabeculectomy & $9(20 \%)$ & $2(2 \%)$ \\
\hline Sinusotomy & 0 & $1(1 \%)$ \\
\hline Laser peripheral iridotomy & $1(2 \%)$ & 0 \\
\hline Argon laser trabeculoplasty & $1(2 \%)$ & $1(1 \%)$ \\
\hline \multicolumn{3}{|l|}{ General risk factors } \\
\hline Dementia & $7(16 \%)$ & $3(3 \%)$ \\
\hline $\begin{array}{l}\text { Ischaemic heart disease, } \\
\text { cerebrovascular accident/renal } \\
\text { failure }\end{array}$ & $6(13 \%)$ & $13(14 \%)$ \\
\hline Chronic respiratory failure & $1(2 \%)$ & $8(9 \%)$ \\
\hline
\end{tabular}

procedures phacoemulsification and intraocular lens insertion was completed via a corneal or scleral section, following which the trabeculectomy was carried out as described above via a limbus or fornix based conjunctival flap. For single site surgery, phacoemulsification, and intraocular lens insertion was first completed via a scleral tunnel, the lip of which then formed the posterior extent of the scleral flap. The trabeculectomy then proceeded in the standard fashion as previously described.

\section{Early postoperative management}

All patients were seen the day after operation when the IOP was measured and hypotensive medication adjusted to control the IOP. Topical steroids were given four times daily in all cases for several weeks until the eyes were white and quiet. Seven phaco-trab eyes showed signs of excessive bleb fibrosis and were treated by administration of oral prednisone, diclofenac, and colchicine for four weeks. ${ }^{78}$

\section{Adjustment of hypotensive medication}

For patients with Molteno implants, once the drainage tube opened any miotics were discontinued and hypotensive medications adjusted to maintain the IOP in the normal range.

\section{Definition of end points Intraocular pressure}

The preoperative IOP for each eye was taken as the mean IOP in the month before surgery. Postoperatively IOP was taken as the mean for each postoperative year. In 16 eyes where more than a year elapsed between postoperative visits, intervening values were interpolated.

"Control" was defined as a persistent IOP of $21 \mathrm{mmHg}$ or less with or without hypotensive medication. "Failure" was defined as a persistent IOP of more than $21 \mathrm{mmHg}$, repeat drainage operation, or total loss of vision due to complications of the Molteno implant or trabeculectomy.

\section{Visual fields}

Progressive loss of visual field was taken to be any definite reduction in visual field area or extension towards fixation of a paracentral fixation that was due to glaucoma. The degree of loss was determined by comparing scores from visual fields plotted near the operation with those plotted at the latest follow up visit.

\section{Visual acuity}

The preoperative visual acuity for each patient was taken as the best corrected visual acuity recorded in the month prior to surgery. The postoperative visual acuity was taken as the best visual acuity for each postoperative year.

\section{Analysis methods}

Survival methods were used to analyse both the probability of retaining vision and the probability of implant failure. In these analyses censoring was at the last follow up visit for patients who had not experienced an event. Survival curves were calculated using all 139 eyes and estimated the survival probabilities of a randomly selected eye from 122 patients. Survival curves based only on the first eye treated did not differ from those based on all eyes by more than $4 \%$ at any time point. Confidence intervals (CI) and p values were based on data for the first eye treated in each patient which eliminated the effects of the correlation introduced by those patients who underwent bilateral operations. p Values were based on the log rank statistic and CI were calculated using Greenwood's formula. ${ }^{9}$

\section{RESULTS}

Molteno implant insertion was combined with cataract extraction in 45 eyes of 43 patients (ECCE implant: 37 eyes; PHACO implant: 8 eyes). Cataract extraction combined with trabeculectomy was performed in 94 eyes of 79 patients (ECCE-trab: 38 eyes, phaco-trab: 56 eyes). Postoperative follow up in the implant group ranged from 0.3 to 13.4 (mean 5.3 ) years, and in the trabeculectomy group from 0.1 to 14.4 (mean 3.9) years.

Preoperative patient characteristics are shown in Table 1. There were significantly more eyes which had undergone previous trabeculectomy or had corneal guttata in the implant group $(p \leqslant 0.001$ and $p<0.0000$ respectively). There were no significant differences in other risk factors, age at operation, gender distribution, preoperative IOP, number of hypotensive medications, length of follow up, or visual acuity between the two groups.

\section{Operative and postoperative complications}

The postoperative course was generally smooth following all types of procedure. Cataract extraction combined with implant insertion produced a moderate reduction in IOP lasting for 1-7 days, after which the IOP returned to preoperative levels until the Vicryl tie broke down and drainage started approximately five weeks (range 3-7 weeks) after operation. The onset of drainage produced no subjective symptoms and was detected by a fall in IOP and the presence of distended blebs over the plates of the implants. 
Operative complications

Operative complications included two posterior capsule tears, one with associated vitreous loss in the phaco implant series. There were no complications related to the trabeculectomy or implant component of any procedures.

\section{Early postoperative complications and surgical re- interventions}

Early postoperative complications included hyphaema, anterior chamber shallowing, choroidal detachment associated with varying degrees of hypotony, IOP spikes greater than $30 \mathrm{mmHg}$, and iris prolapse. There were no significant differences in the nature or incidence of these complications between the implant or trabeculectomy group or different techniques of cataract extraction.

One flat anterior chamber following a phaco-trab was reformed with viscoelastic.

Acute elevation of IOP to more than $30 \mathrm{mmHg}$ was noted in one patient following an ECCE-trab and two following a phaco-trab on the first postoperative day. In one eye, aspiration of viscoelastic was subsequently performed, and normalisation of IOP occurred after a short course of hypotensive therapy in the other cases.

Iris prolapse, which required repositing and peripheral iridectomy, occurred in one patient following ECCE-trab. Diplopia, which spontaneously resolved after two months, occurred in one eye following ECCE implant. No suprachoroidal haemorrhages occurred. Intraocular lens exchange was performed in one eye following phaco implant.

\section{Threatened primary bleb failure}

Seven patients who had undergone cataract extraction combined with trabeculectomy showed signs of primary bleb failure and were treated with combined administration of oral prednisone, diclofenac, and colchicine. ${ }^{78}$ All cases responded well, with reduction in bleb inflammation and the establishment of diffusely spreading blebs with good control of IOP assisted by bleb needling in one case.

Later surgical intervention (>6 months postoperatively)

Later intraocular procedures included penetrating keratoplasty (five eyes), further filtration/implant surgery (two eyes), laser posterior capsulotomy ( 10 eyes) and removal of a fibrous membrane anterior to the intraocular lens (two eyes).

Of the five eyes requiring penetrating keratoplasty, one had undergone a phaco-trab and was successfully treated by keratoplasty combined with insertion of an implant. Of the four cases that had undergone ECCE drains, two had undergone previous trabeculectomy. Of the two cases in which corneal graft was performed after combined cataract implant surgery, one case had pre-existing cornea guttata while the corneal decompensation in the second followed catastrophic circulatory collapse associated with major abdominal surgery 12 months after operation.

\section{Visual field}

There were no significant differences between the two groups in terms of area of visual field remaining at the time of operation (table 1) or in presence of progressive field loss which was recorded in 10 of 45 (22\%) implant eyes and 18 of $88(20 \%)$ trabeculectomy eyes.

\section{Visual acuity}

The preoperative visual acuity in both groups ranged from $1 /$ 60 to 6/3-6/9. Postoperative visual acuities improved in both groups to $20 / 35$ in the implant group and 20/30 in the trabeculectomy group at one year. Subsequently, a progressive decline in visual acuity in both groups occurred, with mean acuities at 10 years of 20/50 and 20/60 in the implant and trabeculectomy groups respectively.

\section{Intraocular pressure}

Preoperatively there was no significant difference in mean IOP or number of hypotensive medications between the two groups. In the implant group the mean IOP was $15.04 \mathrm{mmHg}$ on 0.93 medications at the end of the first year postoperatively falling progressively to $12.4 \mathrm{mmHg}$ on 0.43 medications by 10 years. In the trabeculectomy group the mean IOP was $15.39 \mathrm{mmHg}$ on 0.14 medications at the end of the first year postoperatively and remained between 14.5 and $16.7 \mathrm{mmHg}$ on 0.3 to 0.37 medications for the next nine years.

In the implant group, IOP control was achieved in all cases with no hypotensive medication required at one, two, and five years in $21 \%, 54 \%$, and $59 \%$ respectively. In the trabeculectomy group, IOP control was achieved in 88 eyes (94\%) with no hypotensive medications required at one, two, and five years in $90 \%, 78 \%, 64 \%$ respectively.

Trabeculectomy failure occurred in 6/94 eyes (6.4\%). After 10 years, the estimated control rate was 1.0 and 0.73 in the implant and trabeculectomy groups respectively. Control of IOP was significantly better after insertion of Molteno implants compared with trabeculectomy $(p<0.03)$. See Figure 1.

\section{DISCUSSION}

This study compared the results of cataract extraction combined with insertion of a Molteno implant or trabeculectomy in 45 and 94 eyes respectively with primary glaucoma. Cataract extraction combined with Molteno implant insertion using the Vicryl tie technique was shown to be a safe operation with a low incidence of operative and postoperative complications that gave good long term control of IOP in all cases. All patients were followed up prospectively, which reduced uncertainty resulting from selective attendance and incomplete follow up.

\section{Operative and postoperative complications}

The incidence of complications was low, with no significant differences in their nature or frequency between the two groups.

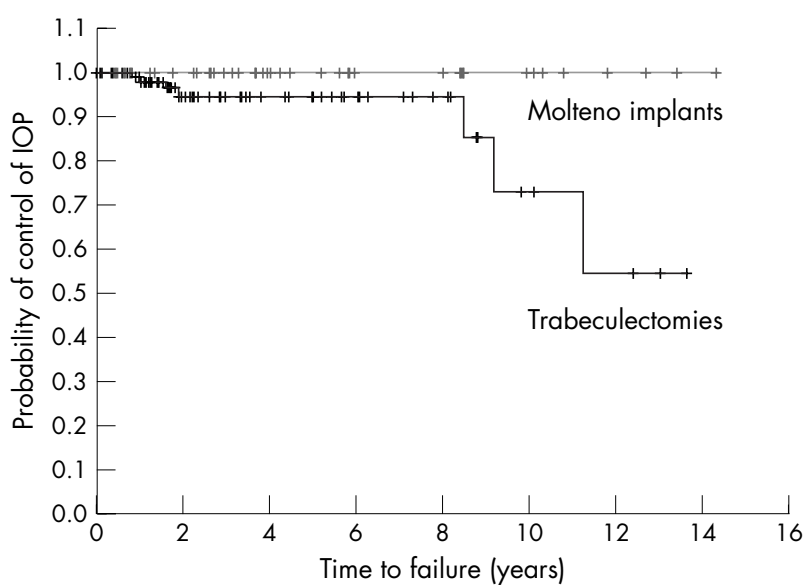

Figure 1 Kaplan-Meier curves showing the probability that the intraocular pressure will be controlled at $21 \mathrm{mmHg}$ or less after cataract extraction combined with either Molteno implant insertion or trabeculectomy. Each "tick" represents a censored observation, that is, the time of death or latest follow up for a single eye. 
Cataract extraction complications

Our vitreous loss rate of $2 \%$ in implant eyes and $0 \%$ of trabeculectomy eyes is similar to the $0 \%-12.5 \%$ reported in other series. ${ }^{10-12}$

\section{Late corneal decompensation}

Corneal decompensation after insertion of Molteno implants has been reported,,$^{13-17}$ but it has been difficult to define the role of the implant in severely damaged eyes that have already undergone numerous intraocular procedures. The study by McDermott et al of the effect of Molteno implants on corneal endothelial cells showed that correctly placed drainage tubes had no effect on endothelial cell count. ${ }^{18}$ In four of the five eyes requiring penetrating keratoplasty in this series, corneal decompensation was associated with pre-existing risk factors or complications unrelated to implant insertion.

\section{Control of IOP}

Intraocular pressure control improved in both groups. The results in the trabeculectomy group were similar to those of shorter term studies of phaco-trab in low risk patients. ${ }^{109-23}$ It is of interest to compare the results of this study with the larger series of primary glaucoma with additional risk factors drained by implants ${ }^{6}$ and primary glaucoma drained by trabeculectomy $y^{5}$ previously reported from this institution. In the case of cataract extraction combined with implants, the behaviour of the IOP was similar to that observed in the larger series of primary glaucoma with risk factors, with most cases showing a progressive fall in IOP and reduction in the need for hypotensive medication. In the case of cataract extraction combined with trabeculectomy the long term outcome was less favourable, with a tendency for the mean IOP to rise after one year. This trend consisted of cases in which drainage improved with time, and others where drainage deteriorated. One major difference between the two procedures was that trabeculectomy gave good results initially which deteriorated with time while implants gave good initial control of IOP which improved with time. Another difference was the need for postoperative hypotensive medication. Trabeculectomy used less medication initially and the proportion requiring medication increased with time, so that after five years the proportion requiring hypotensive medication exceeded that of cases drained by implant.

This series has shown that combined cataract extraction and Molteno implant insertion gave comparable results to phacotrabeculectomy with regard to visual acuity and visual field progression with significantly better long term control of IOP.

\section{ACKNOWLEDGEMENTS}

The Healthcare Otago Charitable Trust provided financial support for this study.

\section{Authors' affiliations}

A C B Molteno, K W Whittaker, T H Bevin, Section of Ophthalmology, Department of Medical and Surgical Sciences, University of Otago Medical School, Dunedin, New Zealand

P Herbison, Department of Preventive and Social Medicine, University of Otago Medical School, Dunedin, New Zealand
Correspondence to: Professor A C B Molteno, Section of Ophthalmology, Department of Medical and Surgical Sciences, University of Otago Medical School, P O Box 913, Dunedin, New Zealand; georgi.bond@healthotago.co.nz

Proprietory interest: ACB Molteno declares a financial interest in Molteno implants. None of the other authors has any competing interests.

Accepted for publication 15 May 2003

\section{REFERENCES}

1 Luntz MH, Berlin MS. Combined trabeculectomy and cataract extraction. Advantages of a modified technique and review of current literature. Trans Ophthalmol Soc U K 1980;100:533-41.

2 Casson RJ, Salmon JF. Combined surgery in the treatment of patients with cataract and primary open-angle glaucoma. J Cataract Refract Surg 2001;27:1854-63.

3 Storr-Paulsen A, Bernth-Petersen P. Combined cataract and glaucoma surgery. Curr Opin Ophthalmol 2001;12:41-6.

4 Molteno ACB, Polkinghorne PJ, Bowbyes JA. The vicryl tie technique for inserting a draining implant in the treatment of secondary glaucoma. Aust N Z J Ophthalmol 1986;14:343-54.

5 Molteno ACB, Bosma NJ, Kittelson JM. Otago Glaucoma Surgery Outcome Study. Long-term results of trabeculectomy-1976 to 1995. Ophthalmology 1999:106:1742-50

6 Molteno ACB, Bevin TH, Herbison P, et al. Otago Glaucoma Surgery Outcome Study. Long-term follow-up of cases of primary glaucoma with additional risk factors drained by Molteno implants. Ophthalmology 2001;108:2193-200.

7 Molteno ACB, Dempster AG. Methods of controlling bleb fibrosis around draining implants. Glaucoma. In: Mills KB, ed. Proc of the Fourth Int'l Symp of the Northern Eye Institute. New York: Pergamon Press, 1988:192-21 1

8 Fuller JR, Bevin TH, Molteno ACB, et al. Anti-inflammatory fibrosis suppression in threatened trabeculectomy bleb failure produces good long term control of intraocular pressure without risk of sight threatening complications. Br J Ophthalmol 2002;86:1352-5.

9 Collett D. Modelling Survival Data in Medical Research. New York: Chapman \& Hall, 1994.

10 Wishart PK, Austin MW. Combined cataract extraction and trabeculectomy: phacoemulsification compared with extracapsular technique. Ophthalmic Surg 1993;24:814-21.

11 Peräsalo R. Phaco-emulsification of cataract in eyes with glaucoma. Acta Ophthalmol Scand 1997;75:299-300.

12 Park HJ, Weitzman M, Caprioli J. Temporal corneal phacoemulsification combined with superior trabeculectomy. Arch Ophthalmol 1997:115:318-23.

13 Mills RP, Reynolds A, Emond MJ, et al. Long-term survival of Molteno glaucoma drainage devices. Ophthalmology 1996;130:299-305.

14 Price FW Jr, Wellemeyer M. Long-term results of Molteno implants. Ophthalmic Surg 1995;26:130-5.

15 Lloyd MA, Sedlak T, Hever DK, et al. Clinical experience with the single-plate Molteno implant in complicated glaucomas. Update of a pilot study. Ophthalmology 1992;99:679-87.

16 Molteno ACB. The use of draining implants in resistant cases of glaucoma. Late results of 110 operations. Trans Ophthalmol Soc NZ 1983;35:94-7.

17 Sherwood MB, Smith MF, Driebe WT Jr, et al. Drainage tube implants in the treatment of glaucoma following penetrating keratoplasty. Ophthalmic Surg 1993;24:185-9.

18 McDermott ML, Swendris RP, Shin DH, et al. Corneal endothelial cell counts after Molteno implantation. Am J Ophthalmol 1993;115:93-6.

19 Shingleton BJ, Jacobson LM, Kuperwaser MC. Comparison of combined cataract and glaucoma surgery using planned extracapsular and phacoemulsification techniques. Ophthalmic Surg Lasers 1995;26:414-9.

20 Lyle WA, Jin JC. Comparison of a 3- and 6-mm incision in combined phacoemulsification and trabeculectomy. Am J Ophthalmol 1991;111:189-96.

21 Guggenbach M, Mojon DS, Böhnke M. Evaluation of phacotrabeculectomy versus trabeculectomy alone. Ophthalmologica 1999;213:367-70.

22 Tezel G, Kolker AE, Kass MA, et al. Comparative results of combined procedures for glaucoma and cataract: 1. Extracapsular cataract extraction versus phacoemulsification and foldable versus rigid intraocular lenses. Ophthalmic Surg Lasers 1997;28:539-50.

23 Kosmin AS, Wishart PK, Ridges PJG. Long-term intraocular pressure control after cataract extraction with trabeculectomy: Phacoemulsification versus extracapsular technique. J Cataract Refract Surg 1998;24:249-55. 